\title{
Business-as-Usual will not Deliver the COVID-19 Vaccines We Need
}

\author{
Els Torreele ${ }^{1}$
}

Published online: 9 November 2020

(c) Society for International Development 2020

\begin{abstract}
Governments must become active shapers of medical innovation and drive the development of critical health technologies as global health commons. The 'race' for COVID-19 vaccines is exposing the deficiencies of a business-as-usual medical innovation ecosystem driven by corporate interests, not health outcomes. Instead of bolstering collective intelligence, it relies on competition between proprietary vaccines and allows the bar on safety and efficacy to be lowered, risking people's health and undermining their trust.
\end{abstract}

Keywords Medical innovation $\cdot R \& D$ governance $\cdot$ Vaccination $\cdot$ Collective intelligence Open science $\cdot$ Transparency Vaccine safety and efficacy

In the early weeks of 2020, the world was alerted to the emergence of a new deadly infectious respiratory disease, COVID-19, caused by severe acute respiratory syndrome coronavirus 2 (SARS-CoV-2). First reported in China, it rapidly spread across the globe. Without effective treatments or vaccines available, the response to the pandemic has so far largely relied on infection control measures such as hand hygiene, personal protective equipment including masks, physical distancing and restrictions on movement which have included variable periods of lockdown of cities, countries or regions. By late September, over one million people had died from COVID-19, among over 33 million people diagnosed.

Given the enormous health, social and economic impact of the continued spread of COVID-19, which is nowhere near being under control, it is no surprise that a lot of hope is set on finding a vaccine. With massive financial support from governments, in particular the US, the UK, other European countries, as well as China and Russia, researchers and companies engaged in what soon became a frantic race to develop vaccines against COVID-19. So far, an unprecedented amount of public funds (estimated at over 5 Bn US\$) ${ }^{1}$ has been poured into vaccine research and development

Els Torreele

Els.Torreele@protonmail.com

1 Institute for Innovation and Public Purpose (IIPP), University College London, London, UK
(R\&D) and manufacturing, resulting in over 50 vaccine candidates in clinical trials ${ }^{2}$ and many more in the pipeline.

Touted by many as a major tour de force, the ongoing 'race' towards a vaccine is also exposing the intrinsic deficiencies of relying on for-profit pharmaceutical companies, that are governed by trade rules, financial speculation and market competition, to ensure the development of essential health technologies. In fact, it risks delivering vaccines that are neither adequate nor widely accessible and may stand in the way of a truly effective global response to the pandemic.

\section{Vaccines are Public Health Interventions, not Ordinary Commodities}

Vaccinating against infectious diseases has proven to be a highly cost-effective public health intervention, combining individual and population-wide health benefits, if certain conditions are met. These are in the first place that the vaccine(s) must be safe and effective, and widely available to vaccinate the populations that can most benefit from it. Depending on the disease, how it is transmitted and how contagious it is, an effective vaccine would ideally protect against infection, or else, it may only protect from getting (seriously) ill, or dying, or from further spreading the disease. An additional condition is that vaccines be deployed

\footnotetext{
1 https://www.policycure srese arch.org/covid-19-r-d-tracker. Accessed 15 Oct 2020.

2 https://www.nytimes.com/interactive/2020/science/coronaviru s-vaccine-tracker.html. Accessed 15 Oct 2020.
} 
through an appropriate vaccination strategy. Who and when to vaccinate, including priority allocation if vaccine availability is limited, are informed both by the epidemiology and the vaccine's properties, and may need to be adapted over time as the pandemic evolves and more vaccines become available.

Vaccine development and optimal use as public health intervention therefore depends on continuous data-driven assessment of benefits and risks in the context of the evolving pandemic, with the view of maximizing the public health impact of vaccination strategies. This is particularly important during a public health emergency like COVID-19, where vaccine development, regulatory review of candidates and their deployment will occur under intense clinical, economic, and political pressure (Avorn and Kesselheim 2020).

The way in which the commercial and geopolitical 'race' for a vaccine is playing out, however, risks side-lining these critical public health objectives in an R\&D process that hinges on the privatization and commercialization of knowledge, and is focused on being first to get a vaccine to market (Torreele 2020a). There currently is no mechanism to ensure that the best possible vaccines are being developed and deployed.

\section{Collective Intelligence not Proprietary Competition Would Deliver Best Vaccines}

The classic approach to vaccine development is that private companies invest in R\&D based on their own proprietary platform technologies (vectors, delivery systems, adjuvants), ${ }^{3}$ in which they integrate a specific antigen to adapt to the target disease.

Despite a pipeline of nearly 200 vaccine $R \& D$ projects, the 'race' to get a vaccine to market fastest does not incentivize the best science for public health interest. Instead, it favours fragmentation and secretive competition, and precludes the free exchange of knowledge and learning from each other's successes and failures in real time, or a public health-driven and collaborative portfolio approach. None of the individual elements of each proprietary platform is necessarily the best suited for a COVID-19 vaccine, but each company will only research within the boundaries of the its proprietary technology (covered by patents), hands tied from

\footnotetext{
${ }^{3}$ A vaccine essentially comprises three distinct functionalities: the antigen which is specific to the pathogen being targeted and will be recognized by a person's immune system, a way to get the antigen into the body and present to the immune system, through specialized vectors and/or delivery systems, and an adjuvant to help activate the immune system and direct it towards certain types of responses (e.g. induction of antibodies, or rather a cellular response, or a combination of both dependent on what is believed to provide the best protective immunity).
}

using other and possibly better fit elements that are owned by competitors.

This is antithetical to a collective intelligence effort that would allow scientists all over the world to creatively combine the best elements of our medical knowledge and technological advances into a diverse and innovative portfolio of vaccine candidates with the best chance to achieve our common public health goal (Torreele 2020b). Failing moreover to compare the performance of the different candidates directly, the current process is bound to create a portfolio of suboptimal candidates that are neither the best in their class, nor diverse or complementary. In our supply-driven innovation system (in which the market is considered the ultimate arbiter), there is no public health mechanism to demand or impose that companies develop products according to pre-set and public health-driven performance criteria. As a result, less than optimal candidates can move through the pipeline, if sufficient resources are poured into it.

\section{What Should We Expect from a COVID-19 Vaccine, but are not Getting?}

In April 2020, the World Health Organization (WHO) published a Target Product Profile ${ }^{4}$ (TPP) for COVID-19 vaccines with minimal and ideal vaccine characteristics to guide developers. It lays out safety and efficacy targets, to be demonstrated in people of all age groups, ethnicities and including subpopulations with certain co-morbidities. The WHO Target Product Profile also outlines preferred features to make the vaccine well-suited for a large-scale interventions, for instance good temperature stability and a single dose regimen, or scalable and low-cost manufacturing.

Unfortunately, WHO's target product profiles are only aspirational and vaccine developers are under no obligation to comply with such criteria and ensure the products they are developing will be adequate as a public health intervention. And regulatory authorities are not empowered to demand that either.

While there exists no absolute threshold for vaccine efficacy, WHO's TPP proposes that vaccines should have a minimum efficacy of $50 \%$ to be a useful tool against COVID- 19 . To effectively curb the pandemic and reach adequate population immunity, it has been calculated that vaccines should be $70-80 \%$ effective in preventing infections (Bartsch et al. 2020). It remains uncertain how useful vaccines with much lower efficacy can be, or vaccines that only reduce disease severity, or only work in certain subpopulations (Avorn and Kesselheim 2020). In any case, the TPP and the different

\footnotetext{
${ }^{4}$ https://www.who.int/blueprint/priority-diseases/key-action/WHO_ Target_Product_Profiles_for_COVID-19_web.pdf.
} 
ways in which vaccines can work must be considered when designing clinical trials for COVID-19 vaccine candidates.

\section{Designing Clinical Trials for Speed, Rather than to Establish the Vaccine's Clinical Relevance}

In the current R\&D model, it is left at the discretion of companies to set the vaccine efficacy targets they will measure in the clinical trials, which moreover they design, conduct and analyze themselves, notwithstanding the conflict of interest given their vested interest in the outcome (Quigley 2017). Moreover, the study protocols that detail what is being compared in such trials, and how meaningful differences are going to be measured, are generally kept confidential for the public, as are the full study data and analyses. ${ }^{5}$

A milestone resolution on transparency around medical R\&D was passed at the 2019 World Health Assembly (Fletcher 2019), yet governments so far have failed to implement these commitments, despite huge financial investments in COVID-19 R\&D that could have been used as leverage to demand transparency on scientific methods and data, as well as clinical trial costs, and set performance targets for the vaccines.

As companies' primary goal is to obtain marketing approval from regulators, they will design trials in ways that gives the fastest and easiest way to success, which does not necessarily coincide with asking the clinically most relevant questions. When front running COVID-19 vaccine developers Moderna, Pfizer, and AstraZeneca ceded to public pressure and shared their phase III trial protocols, we learnt that they are indeed designed to get quick answers, not to demonstrate the vaccines are truly effective (Doshi and Topol 2020). And while the three protocols differ in the details of how they measure efficacy (which conveniently will make the results impossible to compare) they all look at reducing the number of mild COVID-19 cases as primary endpoint. The more clinically relevant endpoint of reducing severe disease and death would take longer to achieve (given that only a minority of those infected develop severe disease), as would demonstrating that the vaccine protects against infection altogether-which is the most desirable form of efficacy.

WHO has proposed a collaborative efficacy trial, called 'Solidarity', ${ }^{6}$ that would allow to directly compare the performance of different vaccines in light of the TPP. However, commercial vaccine developers prefer to set up their own placebo-controlled trials rather than have their vaccines

\footnotetext{
${ }^{5}$ Supposedly because they contain commercially sensitive information, but making independent scrutiny on methodology impossible.

${ }^{6}$ https://www.who.int/blueprint/priority-diseases/key-action/Outli ne_CoreProtocol_vaccine_trial_09042020.pdf.
}

compared to other candidates by independent researchers and held up to stringent public health targets. And while contrary to good scientific practice, governments too have chosen speed and political expediency over quality, generously supporting company trials as part of their geopolitical vaccine race through funding and access to public clinical trial infrastructure and capabilities. Meanwhile, leading scientists advising WHO are left to plead in scientific journals for trials to look for 'worthwhile efficacy' (Krause et al. 2020), lacking ways to impose public health imperatives to commercial developers.

Only radical transparency of clinical trial protocols and data, and a robust and independent review of the results will allow to ensure we fully understand the performance, and limitations, of each vaccine, and restore trust that study conclusions are valid (Torreele 2020c). Amidst growing antiscience and anti-vax tendencies, it is critical that commercial and other vested interests are being removed from the assessment of COVID-19 vaccines, allowing public health scientists, vaccination experts and other relevant stakeholders full access to the data and analyses to redress the already shaken public confidence in public health interventions to control COVID-19 (Jha 2020).

A further risk of focusing on speed is that researchers may not take the time to work with communities to educate them about COVID-19, its risk, the promise of vaccines and the mechanics of developing them, including doing trials, and get communities on board for trials and use of the vaccine. In addition to the risks of suboptimal research ethics practices, this may also create barriers and delays for rollout afterwards, because of distrust, vaccine refusal, science misconceptions, etc.

\section{We Lack the Right Incentives and Goalposts to Generate the Vaccines We Need}

The vaccine $R \& D$ playing field is not designed to enable the best COVID-19 vaccines to move forward based on scientific and public health merit. Instead, it is shaped by wealthy countries and powerful actors like pharmaceutical corporations who place their bets (Knaus 2020)-allotting large amounts of money to propel a chosen candidate forward towards (possible emergency use) authorization. Financial and industrial backing such as through Operation Warp Speed, ${ }^{7}$ more than desirable product characteristics, will determine the likely winners of this race, for which the primary finish line is obtaining marketing approval-typically at the United States Food and Drug Administration (FDA) and/or the European Medicines Agency (EMA). Yet

\footnotetext{
7 https://www.defense.gov/Explore/Spotlight/Coronavirus/OperationWarp-Speed/.
} 
the criteria used by regulators to allow a vaccine on the market are not necessarily responding to the critical question at hand: which vaccine has the potential to significantly impact global public health outcomes for COVID-19?

The primary role of regulatory authorities is to safeguard the public against exposure to potential harmful products. Regulators will assess the potential benefits and risks of individual vaccines based on the company's data and determine whether the presented benefit/risk balance justifies commercialization of that vaccine. It is not the role of regulators to determine if a vaccine is adequate to control the pandemic, nor prioritizing which one has better safety and efficacy. Notably, in their decisions to give marketing authorization, regulators are not taking into consideration a company's intention to produce a vaccine at scale or make it available widely, nor what price they are planning to charge. This means that companies have no incentive nor obligation to prioritize anything else but speed in obtaining marketing approval, based on self-chosen measures of efficacy.

In addition, as the race for a vaccine became fuelled by political, financial and populist pressures, regulatory authorities may not even be able to protect us from harm or futility. Concerns among scientists and experts are growing over the political pressure the US administration is putting on the FDA. Especially the announcement that the FDA would consider emergency authorization for COVID-19 vaccines before phase 3 trials are complete, ${ }^{8}$ has caused concern. If that happens, European countries will be hard pressed to follow suit. Yet, as vaccine and public health experts keep emphasizing, robust phase 3 efficacy trials are the only way to establish whether a vaccine is effective in protecting against infections and disease, and safe to administer to large groups. ${ }^{9}$

\section{Vaccine Innovation Does not Fit a Commercial Business Model}

Having become increasingly financialized (Lazonick et al. 2019), pharmaceutical corporations will not invest in R\&D for products that do not constitute guaranteed and profitable business opportunities. Despite the excellent public health value of vaccines, producing and selling vaccines is considered unattractive from a commercial perspective. Mass manufacturing and distribution of low-cost products, with only marginal profits per unit, compares poorly to the growing medicines market with its uniquely profitable lowvolume specialty drugs for which companies can charge very

\footnotetext{
8 https://edition.cnn.com/2020/08/30/health/fda-covid-19-vaccineeua/index.html.Accessed 15 October 2020.

9 Eric Topol interviewing Paul Offit, https://www.medscape.com/ viewarticle/936937. Accessed 15 October 2020.
}

high prices. At the same time, the $R \& D$ process for vaccines is typically lengthy and costly, with large clinical trials required to demonstrate that it will be safe to administer a product to many millions essentially healthy people, and also effective in protecting against a given disease. Only a handful of companies dominate the global vaccine market, selling essentially variations of the same 10-15 existing vaccines, with relatively little innovation in new disease areas, despite many infectious diseases that could benefit from a vaccine.

Emerging infectious diseases are a case in point. As exemplified again with the 2014-2016 West African Ebola outbreak that killed over 11,000 people, commercial R\&D fails to deliver needed health technologies for outbreaks of infectious diseases. Despite knowing the Ebola virus and its lethal epidemic potential since the 1970s, and vaccine research having advanced in the public sector, there was neither treatment nor vaccine available when a long expected major outbreak devastated Guinea, Liberia and Sierra Leone, and caused a global panic (Torreele and Olliaro 2014). And while a consortium of mainly public partners came together to conduct a clinical trial in 2016 that demonstrated the safety and efficacy of a vaccine candidate, initially developed by Canadian public health researchers ${ }^{10}$ and later licensed to Merck, there was still no registered vaccine available when a new Ebola outbreak hit DRC in 2018-2019. ${ }^{11}$

\section{Mobilizing Public Responsibility to Drive Essential Vaccine R\&D, Yet Privatizing the Outcomes}

Affirming the need for public responsibility to drive R\&D to improve outbreak preparedness, a group of countries and donors came together in the wake of the West African Ebola crisis to create the Coalition for Epidemic Preparedness Innovations (CEPI), ${ }^{12}$ with the mandate to accelerate development of vaccines against outbreak diseases and ensure access. With a massive injection of public and philanthropic funds, in 2017 CEPI started financing public-private partnerships aiming to bring candidate vaccines for MERS-CoV (also a coronavirus), Lassa Fever and Nipah forward. In parallel, CEPI also invested in generic vaccine technology platforms that could be quickly adapted to any emerging infection of a so far unknown pathogen, the socalled 'disease-X' (Simpson et al. 2020).

As soon as SARS-CoV-2 emerged, CEPI mobilized funds to apply existing vaccine technologies to COVID-19,

\footnotetext{
$\overline{10}$ https://www.cbc.ca/news/health/ebola-vaccine-national-micro biology-laboratory-pharmaceutical-industry-scientists-1.5429060, Accessed 15 October 2020.

11 https://www.theeastafrican.co.ke/scienceandhealth/High-risk-eastafrica-to-use-trial-Ebola-vaccine/3073694-5131542-8qrxmi/index .html, Accessed 15 October 2020.

12 https://cepi.net/, Accessed 15 October 2020.
} 
piggybacking on earlier investments in disease-X and MERS-CoV programmes, thus quickly moving several candidates into clinical trials. Taking advantage of the massive public subsidies that started flowing towards COVID19 R\&D, both small biotechs and major pharmaceutical companies jumped on the opportunity to adapt or reorient their proprietary vaccine technology platforms towards COVID-19, allowing to fast-track what otherwise would require many years of research. For instance Moderna's and BioNTech/Pfizer's leading mRNA vaccine candidates built on 30 years of public and private research into the potential of RNA and DNA vaccines (yet none of them made into a vaccine approved for human use) (Akpan 2020). Similarly, Oxford University (who later partnered with AstraZeneca), $\mathrm{J} \& \mathrm{~J}, \mathrm{CanSino}$ and Gamaleya have rapidly repurposed for COVID-19 their adenovirus-based vaccine platforms which had been explored for many years and a variety of diseases, including most recently MERS-CoV, Zika and Ebola. ${ }^{13}$

Despite each of these R\&D efforts building on a wealth of earlier research by the global vaccine research communitymuch of which is traditionally done and funded by the public sector-the basis of our commercial R\&D model is that universities and companies are allowed to appropriate such technology platforms as their own. Governed by the World Trade Organization's 1995 TRIPS agreement that obliged countries to grant and enforce patents on pharmaceutical 'inventions', medical knowledge and technologies have largely been privatized, owned and traded as commodities, even when of critical public health importance. As a result, vaccine candidates essentially move through the pipeline as speculative commercial assets, whose market valuation can be followed through the share price of the companies owning them. ${ }^{14}$ While governments generously subsidize the COVID-19 vaccines candidates of a handful of companies, it is unclear whether the financing agreements are structured to recognize this co-investment and ensure there will be commensurate sharing of the resulting outcomes in terms of access and pricing (the agreements have remained confidential).

\section{The New Monopolies: Vaccine Manufacturing and Supply Capacity}

Realizing that providing global access to an eventual COVID-19 vaccine would require manufacturing at unprecedented scale, governments also provided upfront investments

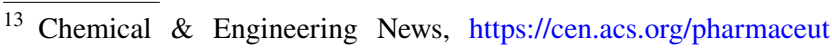
icals/vaccines/Adenoviral-vectors-new-COVID-19/98/i19, Accessed 15 October 2020.

14 Forbes, https://www.forbes.com/sites/greatspeculatio ns/2020/04/24/best-coronavirus-vaccine-stock-moderna-inovio-sanof i-or-johnson-johnson/\#7e6076663b5e, Accessed 15 October 2020.
}

in the companies' manufacturing capacity and infrastructure. Not only have they agreed to massively finance the expansion of private vaccine manufacturing infrastructure, with seemingly little or no strings attached, they also agreed to pay for the actual manufacturing of large volumes of selected vaccines before their safety and efficacy is proven and committed to buy large volumes once they were approved (at undisclosed prices) through so-called advance purchase commitments (APCs) ${ }^{15}$. On top of this, companies have negotiated confidential liability transfers to governments, in case the vaccines would exhibit side effects that were not observed in the accelerated $R \& D$ process (Halabi et al. 2020).

In contrast to generic drug manufacturing, there is relatively little vaccine manufacturing capacity able to produce at large scale outside of the major (Western) vaccine corporations, with the notable exception of the Serum Institute of India, that has taken many years to build its meanwhile state-of-the-art capability. While strictly speaking there is no such thing as generic vaccines, vaccine manufacturing is technologically much more complex than small chemicals, and setting up the production of an existing vaccine typically requires lengthy technology transfer, including know-how sharing, for a newcomer to become operational. The massive investments of governments into scaling up manufacturing capacity for the COVID-19 candidates seem to have all gone into private companies under license from the 'originator' companies, which is a missed opportunity for the global health community to have invested in expanding the global technological capacity to produce vaccines as commons, and start challenging the oligopoly that now exists among major vaccine producers.

Taken together, the unprecedented public investments in R\&D and manufacturing capacities for COVID-19 vaccines, and the purchase commitments and liability transfers, all directly benefit companies that 'own' these technologies, and have come with little or no strings attached, de facto privatizing all those public investments and the control over potentially hugely important public health interventions, which essentially should have been global health commons.

\section{Why a Poorly Effective Vaccine Can Do More Harm than Good}

Vaccines are a public health intervention which, more than any other, require people's collective buy-in and trust. While some people argue that having a COVID-19 vaccine that works a little, and for some, is better than having no vaccine at all, there are major risks and opportunity costs for

\footnotetext{
15 https://www.dw.com/en/coronavirus-vaccine-nationalism-covid -19-us-germany-gavi/a-54634662, last accessed 4 November 2020
} 
prioritizing speed over adequate efficacy and safety. Roll-out of a weakly effective vaccine in fact could worsen the pandemic in multiple ways (Krause et al. 2020).

If authorities wrongly assume there is a substantial reduction in risk in the population, they may choose to scale down other COVID-19 control measures and re-open the economy. If the pandemic continues to grow despite having massively invested in vaccines, they may not be willing to continue investing in a potentially better next generation vaccines. Similarly, if vaccinated individuals wrongly believe they are protected against infection, compliance with other protective measures such as wearing masks or physical distancing may be lowered. When people realize they get infected despite being vaccinated, their confidence in vaccines may drop, leading them to refuse other more effective vaccines that would become available later on.

Deployment of a marginally effective vaccine could also interfere with the evaluation of other vaccines. It may become challenging to find enough unvaccinated trial volunteers to enrol in new vaccine trials, while conducting a trial in a population that is partially protected due to prior (poorly effective) vaccination may lead to results that are very difficult to interpret. Additionally, once a COVID-19 vaccine gets approved, subsequent vaccine candidates will have to be compared to it rather than to a placebo. As this necessarily will be done via what is called 'non-inferiority' trials, there's a risk that vaccines with even worse performance might still get approved, a methodological quirk which has been referred to as 'bio-creep' (Everson-Stewart and Emerson 2010).

A final collateral effect of poorly effective vaccines is that the legitimacy of scientists and the scientific process might be undermined if researchers cannot prevent commercial interests to overtake quality science.

\section{The Unequal Scramble for Equitable Access}

From the early days of the pandemic, influential voices including UN Secretary-General António Guterres, European President Ursula von der Leyen and political leaders and academics from all continents have argued that the exceptional nature and huge impact of the pandemic justifies that COVID-19 vaccines must be considered 'people's vaccines', ${ }^{16}$ or 'global public goods', or 'global health commons' and be available and affordable (for free) to all. However, this voluntarist discourse has not been followed with consequent actions. Instead, we've seen unapologetic vaccine nationalism (Kamradt-Scott 2020) from the US,

\footnotetext{
${ }^{16}$ UNAIDS, https://www.unaids.org/en/resources/presscentre/press releaseandstatementarchive/2020/may/20200514_covid19-vaccine, Accessed 15 October 2020
}

soon followed by other wealthy countries including the European Commission, signing bilateral deals with companies to reserve the majority of early productions for their own populations in what essentially is an unequal scramble for vaccines (Callaway 2020). A multilateral effort coordinated by WHO in the context of their Accelerated Access to Covid Technologies (ACT-A) initiative to also ensure vaccine availability for poorer countries in parallel (COVAX) ${ }^{17}$ has met with mixed success-lots of verbal support but so far limited concrete financial commitments. It is also being criticized for lack of transparency and representation from the countries for whom COVAX is supposed to deliver solutions. ${ }^{18}$

The main strategy used by governments to 'ensure' access is through signing advance purchase commitments with the front-runner vaccine developers (often in combination with significant investments in $R \& D$ and even manufacturing). While initially designed as a market fixing pull mechanism to incentivize companies to do R\&D in directions they would not otherwise go, governments have perverted APCs to guarantee supply and buy up the first in line positions for once the vaccines become available, without even putting demands in terms of desired product profile or pricing. This further shifts the power imbalance between governments and vaccines companies, who successfully turned the COVID19 crisis to their advantage and positioned themselves as key to the solutions, while largely dictating the terms of engagement, not only for availability and access to vaccines in wealth countries but also globally.

At the same time, acknowledging that there will likely be a period during which supply will not be able to meet demand, difficult discussions are ongoing about (principles for) fair and equitable allocation frameworks, both globally and within countries (Samuel 2020). While it is beyond the scope of this article to go into detail on these, it is important to highlight how allocation frameworks and vaccination strategies cannot be seen independently of the exact profile and characteristics of the available vaccines - which we still don't know.

Most critically however, having left ownership and control over the vaccines to pharmaceutical companies, we do not have a collective and public-health driven governance mechanism that is able to organize and steer vaccine allocation and access in ways that maximize health impact (Mazzucato and Torreele 2020).

\footnotetext{
17 https://www.gavi.org/covax-facility.

18 Third World Network, https://www.twn.my/title2/intellectual_ property/info.service/2020/ip200605.htm, Accessed 15 October 2020.
} 


\section{Solutions: Critical Health Technologies Like Vaccines Should Be Considered Global Health Commons}

The race for a COVID-19 vaccine exposes the many ways in which a proprietary and market-based R\&D model is illsuited, by design, to deliver appropriate vaccines to implement effective vaccination strategies to tackle this pandemic.

Vaccines and other health technologies are particularly suited to be considered global commons and benefit from open scientific collaboration, especially when they protect us against infectious diseases that do not care for national borders, private (intellectual) property, shareholder value or market dynamics. Policy makers all over the world can and must assume responsibility for delivering such global health commons and shape the R\&D ecosystem accordingly.

Driving medical innovation in that direction requires a major shift in how governments see and exercise their role, from by-stander market fixing to proactive entrepreneurial states (Mazzucato 2013). Instead of handing out subsidies and market commitments without strings attached, this means the active steering of innovation towards the desired product characteristics and mobilizing the collective intelligence of researchers globally (Mazzucato 2020). It includes shaping the incentives and rules for public and private sector collaboration, in particular knowledge management, to optimally work together towards achieving the public interest goals. The scientific community, with its wealth of public health and infectious diseases expertise could be a key driver to this effect, redefining health innovation to address public health needs, not commercial success.

These ideas are not as far-fetched as one might thinkthe US Department of Defence, in particular through their Defence Advanced Research Projects Agency (DARPA), has long understood how to steer public and private sector innovators towards national strategic objectives, with distinctive success. DARPA's strategic investments underly the US strength in military and space technologies (Medeiros 2019), and the rise of Silicon Valley (Cameron 2018).

\section{So Why not for Health? An Idea Whose Time has Come}

As exorbitant drug pricing and lack of critical R\&D for life threatening conditions, including the growing threat of antibiotic resistance, exposed the deficiencies of our pharmaceutical R\&D ecosystem, alternatives rooted in the fundamental responsibility of states to actively shape medical innovation for the public interest have been proposed, for instance in the context of the 2016 UN High Level Panel on Access to Medicines (Torreele 2016). In the 2018 People's
Prescription report, ${ }^{19}$ Mazzucato calls for a DARPA for health, HARPA: Health innovation aimed at public value, while more recently, a fully publicly owned pharmaceutical 'industry' was proposed for the US (Brown 2020). While that may sound radical, especially in a US context, it is important to keep in mind that until recently, many countries including in Europe had kept critical parts of the pharmaceutical value chain under the control of the public sector, in particular vaccines (Blume 2017). Countries like Brazil and Thailand still have significant government involvement in their pharmaceutical production, contributing to their relative resilience and autonomy for the production of essential health products, for instance antiretroviral therapy for HIV/ AIDS (Ford et al. 2007). Deprived of access to the global commercial market, Cuba has developed a strong public innovation system for health, responding to the country's health needs (Pérez et al. 2018).

Calls for stronger public leadership in medical R\&D and access, and for transparency, are gaining traction in the context of COVID-19. From the early days, there have been calls to ensure that commercial monopolies do not stand in the way of access, and to consider the Covid-related knowledge and technologies as knowledge commons. ${ }^{20}$ Concrete proposals have been put forward to either share and pool knowledge, for instance through the meanwhile established WHO COVID-19 Technology Access Pool (C-TAB), ${ }^{21}$ or else to not grant or enforce intellectual property rights on them, as the proposal of South Africa and India to the WTO for a COVID-19 Waiver on certain provisions of the TRIPS agreement (Silverman 2020). Open access to knowledge and technologies needed to respond to COVID-19 would be a major step towards more autonomy for countries or regions to produce needed health technologies. It will also require establishing adequate infrastructure and capability and strategic government interventions (finance, science and technology, health systems, industrial policy etc.) to generate such health technologies and make available for the population.

The announcement of EU President von der Leyen to create a European BARDA may be an important step in that direction, ${ }^{22}$ at least for the region. However it will be

\footnotetext{
19 The People's Prescription. IIPP report 2018, https://www.ucl. ac.uk/bartlett/public-purpose/publications/2018/oct/peoples-prescripti on, Accessed 15 October 2020.

${ }^{20}$ Commons Network Team, Pooling Knowledge: Private Medicine vs. Public Health? 12 April 2020, https://www.commonsnetwork.org/ uncategorized/corona-private-medicine-vs-public-health/, Accessed 15 October 2020

21 https://www.who.int/emergencies/diseases/novel-coronaviru s-2019/global-research-on-novel-coronavirus-2019-ncov/covid-19technology-access-pool, Accessed 15 October 2020.

22 https://sciencebusiness.net/news/eu-create-new-biomedical-resea rch-agency-modelled-barda, Accessed 15 Oct 2020.
} 
important to ensure that its focus is squarely on improving people's health outcomes and deliver health technologies that are widely available and accessible. Success must be measured in value for health, not for business. To that effect, this initiative must be firmly rooted in the existing European health innovation infrastructure, for instance through the proposed BIOMED Europa (Florio 2020) that could be adapted after the US National Institutes of Health, except focused of global health commons, not just de-risking the biomedical industry. Collaboration with the private sector is welcomed, but the terms and conditions of the public-private partnerships must be governed by public health benefit (Mazzucato and Torreele 2020), and include open collaboration, sharing of know-how, technologies and infrastructure, and building collective intelligence. Instead of secrecy and competition, this approach embraces radical transparency, both on the scientific methods and data, and financially, detailing each one's contributions in investment and risk taking. To ensure truly global health commons, technology transfer to third countries who wish to develop their own capabilities should be built in from the start.

\section{Conclusion}

Humankind is facing a global health crisis, perhaps the biggest crisis of our generation. The decisions people and governments take now, and the values on which they rely, will likely shape the world for years to come, including our healthcare systems, our economy and our culture. The time has come for global leaders to consider vaccines and other health technologies as global health commons that must be available for all and reshape the medical R\&D ecosystem towards delivering that.

\section{Compliance with Ethical Standards}

Conflict of interest The author declares no conflicts of interest.

\section{References}

Akpan, Nsikan. 2020. Moderna's mRNA vaccine reaches its final phase. Here's how it works, National Geographic 27 July, https ://www.nationalgeographic.com/science/2020/05/moderna-coron avirus-vaccine-how-it-works-cvd/ Accessed 15 Oct 2020.

Avorn, Jerry, and Aaron Kesselheim. 2020. Regulatory Decision-making on Covid-19 Vaccines During a Public Health Emergency. JAMA 324 (13): 1284-1285.

Bartsch, Sarah, Kelly O'Shea, Marie Ferguson, Maria Bottazzi, Patrick Wedlock, Ulrich Strych, James McKinnell, Sheryl Siegmund, Sarah Cox, Peter Hotez, and Bruce Lee. 2020. Vaccine Efficacy Needed for a COVID-19 Coronavirus Vaccine to Prevent or Stop an Epidemic as the Sole Intervention. American Journal of Preventive Medicine 59 (4): 493-503.

Blume, Stewart. 2017. The erosion of public sector vaccine production. The case of the Netherlands, in Christine Holmberg, Stuart Blume and Paul Greenough (eds.) The politics of vaccination. https:// www.manchesteropenhive.com/view/9781526110916/97815 26110916.00014.xml.

Brown, Dana. 2020. Medicine For All: The case for a public option in the pharmaceutical industry, 31 August. https://democracyc ollaborative.org/learn/publication/medicine-all-case-public-optio n-pharmaceutical-industry, Accessed 15 Oct 2020.

Callaway, Ewen. 2020. The unequal scramble for coronavirus vaccines-by the numbers, Nature 24 August. https://www.natur e.com/articles/d41586-020-02450-x. Accessed 15 Oct 2020.

Cameron, Nigel. 2018. The government agency that made silicon Valley, Unherd 19 June. https://unherd.com/2018/06/government -agency-made-silicon-valley/. Accessed 15 Oct 2020.

Doshi, Peter, and Eric Topol. 2020. These Coronavirus Trials Don't Answer the One Question We Need to Know, New York Times 22 Sept. https://www.nytimes.com/2020/09/22/opinion/covid-vacci ne-coronavirus.html. Accessed 10 Oct 2020.

Everson-Stewart, Siobhan, and Scott S. Emerson. 2010. Bio-creep in non-inferiority clinical trials. Statistics in Medicine 29 (27): 2769-2780.

Fletcher, Elaine. 2019. World Health Assembly Approves Milestone Resolution On Price Transparency, Health Policy Watch 28 May. https://healthpolicy-watch.news/world-health-assembly-appro ves-milestone-resolution-on-price-transparency/. Accessed 15 Oct 2020.

Florio, Massimo. 2020. Biomed Europa: after the coronavirus, a public infrastructure to overcome the pharmaceutical oligopoly, CIRIEC working paper 2020/08. http://www.ciriec.uliege.be/wp-content/ uploads/2020/07/WP2020-08.pdf. Accessed 15 Oct 2020.

Ford, Nathan, David Wilson, Gabriela Costa Chaves, Michel Lotrowska, and Kannikar Kijtiwatchakul. 2007. Sustaining access to antiretroviral therapy in the less-developed world: Lessons from Brazil and Thailand. AIDS 21 (Suppl 4): S21-S29.

Halabi, Sam, Andrew Heinrich, and Saad B. Omer. 2020. No-fault compensation for vaccine injury - The other side of equitable access to Covid-19 vaccines, The New England Jounal of Medicine. https://www.nejm.org/doi/full/10.1056/NEJMp2030600.

Jha, Ashish K. 2020. We Need More Transparency in COVID-19 Vaccine Development, Time 18 September. https://time.com/5890216/ transparency-covid-vaccine-development/. Accessed 15 Oct 2020.

Kamradt-Scott, Adam. 2020. Why 'vaccine nationalism' could doom plan for global access to a COVID-19 vaccine, The Conversation 7 September. https://theconversation.com/why-vaccine-natio nalism-could-doom-plan-for-global-access-to-a-covid-19-vacci ne-145056. Accessed 15 Oct 2020.

Knaus, Christopher. 2020. Covid-19 vaccines: pressure is on to ensure they go to the most needy, not the highest bidder, The Guardian 26 April. https://www.theguardian.com/world/2020/apr/27/covid -19-vaccines-pressure-is-on-to-ensure-they-go-to-the-most-needy -not-the-highest-bidder. Accessed 15 Oct 2020.

Krause, Philip, Thomas Fleming, Ira Longini, Ana Maria HenaoRestrepo, and Richard Peto. 2020. COVID-19 vaccine trials should seek worthwhile efficacy. Lancet 396 (10253): 741-743.

Lazonick, William, Öner Tulum, Matt Hopkins, Mustafa Erdem Sakinç, and Ken Jacobson. 2019. Financialization of the U.S. Pharmaceutical Industry, INET working paper 2 December. https://www. ineteconomics.org/perspectives/blog/financialization-us-pharm a-industry. Accessed 15 Oct 2020.

Mazzucato, Mariana. 2020. Capitalism is Broken. The fix begins with a free Covid-19 vaccine, New York Times 8 October. https://www. nytimes.com/2020/10/08/opinion/international-world/capitalism -covid-19-vaccine.html. Accessed 9 Oct 2020. 
Mazzucato, Mariana. 2013. The Entrepreneurial State. London: Penguin Books.

Mazzucato, Mariana, and Els Torreele. 2020. How to develop a Covid19 vaccine for all, Project Syndicate 27 April. https://www.proje ct-syndicate.org/commentary/universal-free-covid19-vaccine-bymariana-mazzucato-and-els-torreele-2020-04. Accessed 15 Oct 2020.

Medeiros, Joâo. 2019. This economist has a plan to fix capitalism. It's time we all listened, Wired 8 October. https://www.wired.co.uk/ article/mariana-mazzucato. Accessed 15 Oct 2020.

Pérez, Rojo, Valenti Pérez, Martínez Trujillo, Morales Suárez, Martínez Torres, Fleitas Estévez, et al. 2018. Science and technological innovation in health in Cuba. Results in selected problems, Rev Panam Salud Publica. 42: e32. https://iris.paho.org/bitstream/ handle/10665.2/34903/v42e322018_eng.pdf.

Quigley, Fran. 2017. Remove the For-Profit Variable from Clinical Drug Trials, Health and Human Rights Journal 21 May. https ://www.hhrjournal.org/2017/05/remove-the-for-profit-variablefrom-clinical-drug-trials/. Accessed 15 Oct 2020.

Samuel, Sigal. 2020. Who should get the Covid-19 vaccine first? The equality vs. equity debate, explained. Vox 23 September. https:// www.vox.com/future-perfect/21439799/covid-19-vaccine-prior ity-access-covax-who. Accessed 15 Oct 2020.

Silverman, Ed. 2020. South Africa and India urge WTO to waive IP rights, widen access to Covid-19 drugs and vaccines. STAT 3 October. https://www.statnews.com/pharmalot/2020/10/03/wtocovid19-coronavirus-patents-india-southafrica/. Accessed 15 Oct 2020.

Simpson, Shmona, Michael Kaufmann, Vitaly Glozman, and Ajoy Chakrabarti. 2020. Disease X: Accelerating the development of medical countermeasures for the next pandemic. The Lancet Infectious Diseases 20 (5): e108-e115.

Torreele, Els. 2020a. The rush to create a Covid-19 vaccine may do more harm than good. BMJ 370: m3209.

Torreele, Els. 2020b. Collective intelligence, not market competition, will deliver the best Covid-19 Vaccines, STAT 10 June. https:// www.statnews.com/2020/06/10/collective-intelligence-not-marke t-competition-deliver-best-covid-19-vaccine/. Accessed 15 Oct 2020.

Torreele, Els. 2020c. As politics trumps science in the race for a vaccine, who will protect public health?, BMJ blogs 16 September. https://blogs.bmj.com/bmj/2020/09/16/els-torreele-as-politicstrumps-science-in-the-race-for-a-vaccine-who-will-protect-publi c-health/. Accessed 15 Oct 2020.

Torreele, Els, and Piero Olliaro. 2014. Ebola in West Africa is a wakeup call. What the Ebola crisis tells us about our failing drug development system. AlJazeera 6 November. https://www.aljazeera. com/opinions/2014/11/6/ebola-in-west-africa-is-a-wake-up-call/. Accessed 15 Oct 2020.

Torreele, Els. 2016. Health Innovation as a Public Good, submission to the UN High Level Panel on Access to Medicines. http://www. unsgaccessmeds.org/inbox/2016/2/28/els-torreele. Accessed 15 Oct 2020.

Publisher's Note Springer Nature remains neutral with regard to jurisdictional claims in published maps and institutional affiliations. 